\title{
Thermal and Mechanical Properties of Microporous Polyurethanes Modified with Reduced Graphene Oxide
}

\author{
Michał Strankowski, ${ }^{1}$ Damian Włodarczyk, ${ }^{1}$ Lukasz Piszczyk, ${ }^{1}$ and Justyna Strankowska ${ }^{2}$ \\ ${ }^{1}$ Department of Polymer Technology, Chemical Faculty, Gdańsk University of Technology, G. Narutowicza 11/12, \\ 80-233 Gdańsk, Poland \\ ${ }^{2}$ Institute of Experimental Physics, Faculty of Mathematics, Physics and Informatics, University of Gdańsk, W. Stwosza 57, \\ 80-308 Gdańsk, Poland \\ Correspondence should be addressed to Michał Strankowski; micstran@pg.gda.pl
}

Received 21 May 2016; Revised 24 August 2016; Accepted 8 September 2016

Academic Editor: Ismet Baran

Copyright (C) 2016 Michał Strankowski et al. This is an open access article distributed under the Creative Commons Attribution License, which permits unrestricted use, distribution, and reproduction in any medium, provided the original work is properly cited.

\begin{abstract}
Microporous polyurethanes (MPU) were modified by adding $0.25 \%-1.25 \mathrm{wt} \%$ of reduced graphene oxide (RGO). The materials were prepared without solvent via in situ polymerization. From a technological point of view, it is very important to obtain functional materials by using reacting compounds only. The thermal characteristics of obtained MPU were investigated using TGA, DSC, and DMA techniques. In comparison to nonmodified microporous polyurethane, the thermal stability and mechanical properties of the modified systems have significantly improved. The temperature corresponding to the maximum degradation rate $\left(T_{\max }\right)$ for nanocomposites containing $1 \%$ and $1.25 \mathrm{wt} \%$ of RGO was $51^{\circ} \mathrm{C}$ higher than that observed for pure microporous PU system. The increase of tensile strength was also observed for matrix with the addition of $0.5 \mathrm{wt} \%$ RGO nanofiller.
\end{abstract}

\section{Introduction}

Graphene is composed of $\mathrm{sp}^{2}$ carbon atoms linked together in a two-dimensional honeycomb-like structure. After discovering it as a theoretical 2D layer material many attempts of effective production have been made. In aspects of industrial implementation graphene and its derivatives have become one of the most important materials in nanotechnology. Scientists from different fields of science, for example, physics, chemistry, and engineering, are trying to find its best allotropic form in matter of functionalization, for example, as fillers used in polymer nanocomposites. Now graphene is one of the most promising materials, although many problems and controversies emerged during investigations of graphene's excellence, for example, in sensors and polymer coatings. Due to its unique structure, graphene has interesting mechanical properties (high Young's modulus, approximately $1 \mathrm{TPa}$, and tensile strength, $130 \mathrm{GPa}$ ) [1-3], very good energy storage, electrical $\left(10^{-8} \Omega \mathrm{m}\right)[4-8]$ and thermal $\left(5300 \mathrm{~W} \mathrm{~m}^{-1} \mathrm{~K}^{-1}\right)[1,2,9-11]$ conductivity, capacity, frequency of response (similar to $\mathrm{Si}$ ), and overall surface area (roughly $2600 \mathrm{~m}^{2} \mathrm{~g}^{-1}$ ) [12-17]. One of the most significant applications nowadays in graphene composites is gas barrier properties; graphene derivatives can act as a retention wall with adsorption abilities [18-20].

Porous derivatives are still being invented and further modified so their parameters could be even more diverse. Methods of derivatives production differ from one scientist to another, for example, using Hummers method which was the best for GO preparation but in time has been improved and even further modified. Reduced graphene oxide produced by this method is characterized by a low number of oxygen functional groups. This implicates that RGO has a better compatibilization effect on the matrix than pure graphene, and it can be easily dispersed in the composite systems [2128]. RGO incorporated into polymer matrix shows even better properties than unmodified graphene polyurethanes. This is happening because PUR's structure is changed by the addition of a filler which reacts chemically with the matrix thanks to single polar groups. Thus it is possible to compose both of these modified materials with advantageous thermoplastic and elastomeric effect: better rigidity, hardness, 


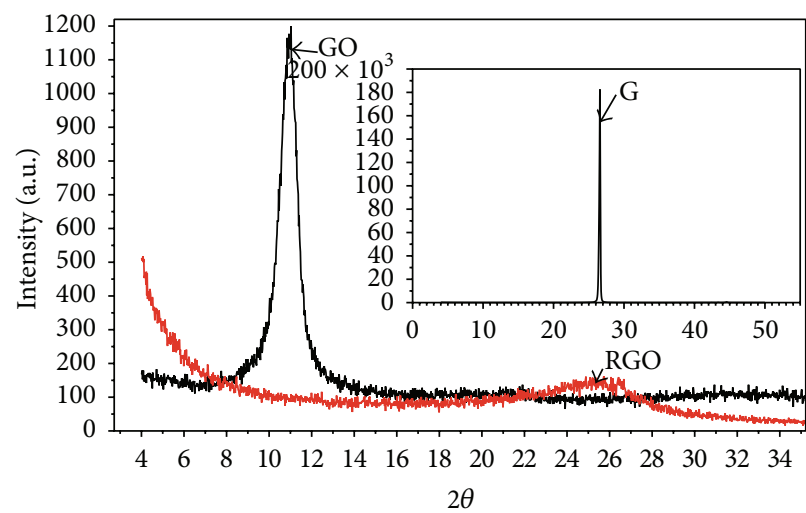

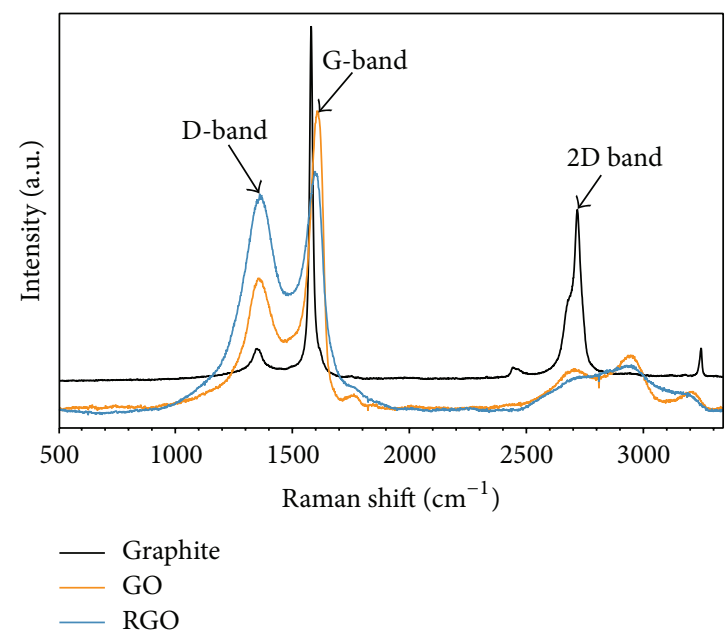

(b)

FIGURE 1: XRD (a) and Raman (b) spectra for graphite (G), graphene oxide (GO), and reduced graphene oxide (RGO).

ductility, and tensile strength. It is worth mentioning that particle size and good dispersion are also very important especially for conductivity which is dependent on percolation threshold.

Systematic evaluations of all of the following composite parameters are being pursued by researchers using SEM, XRD, DMA, Raman, and FTIR methods [29-32]. Raman and FTIR spectroscopies help by acquiring spectra of matrix surface, morphology, and its differences due to characteristic filler content, number of layers, and so forth. XRD technique is used for assessment of GO exfoliation and/or intercalation effects. DMA is irreplaceable in viscoelastic modulus behavior investigation relating to temperature and stress frequency which can be all related to rheology of these materials.

Researchers are putting emphasis on nanosized materials which are common interest nowadays. Versatility of elastomers with graphene is still increasing. Nanocomposites made with it are applicable in various fields, for example, in microwave absorbers, aerospace, inner tubes, sensors, belts, hoses, flooring, and dampers. Now, they are trying to apply it in solar cells, fuel cells, conductive inks, gaskets, artificial muscles, and electronics on larger manufacturing scale [3343].

This paper focuses on the studies of microporous polyurethane systems (MPU) modified via incorporation of reduced graphene oxide. By modifying the polymeric matrix with even a small amount of graphene, we can obtain polyurethane materials with unique mechanical and thermal properties.

\section{Experimental}

\subsection{Materials}

2.1.1. Reagents. Natural flake graphite (NFG, MICRONS850) was provided by Asbury Carbons (P.O. Box 144, 405 Old Main St., Asbury, NJ 08802, USA). Fuming nitric acid $(>90 \%)$, sulfuric acid (95-98\%), potassium chlorate (98\%), and hydrochloric acid (37\%) were obtained from Avantor Performance Materials Poland SA and used as received.

The microporous system, which has been originally used in the shoe sole production, was purchased from MB Market Ltd., Poland. It was based on the polyol (GF422 POL) (A) and crosslinking agent (CROSS.MB/40/4 containing ethane-1,2diol) (B) and isocyanate mixture (GT 991 ISO, 4,4' ${ }^{\prime}$-methylene diphenyl diisocyanate, o-(p-isocyanatobenzyl)phenyl isocyanate, and diphenylomethyl-2, $4^{\prime}$ - diisocyanate) (C).

2.2. Preparation of Reduced Graphene Oxide. Graphene oxide was obtained from natural flake graphite according to modified Hummer's method, described by Marcano et al. [27]. An amount of $100 \mathrm{~g}$ of GO powder was obtained after drying the suspension. Then, reduced graphene oxide was obtained by the thermal reduction, using an oven previously preheated to $200^{\circ} \mathrm{C}$, under argon atmosphere during a 30 min reduction reaction. The final product was verified using SEM and TEM techniques.

Results regarding structural research of reduced graphene oxide (RGO), its substrate, graphite (G), and intermediate product, graphite oxide (GO), are being presented in Figure 1(a). According to diffraction maxima acquired from XRD spectra, distance between graphite layers has been calculated. Maximum of G-band is present at $25^{\circ}(2 \theta)$ which means that interplanar distance is approximately $0.56 \mathrm{~nm}$. In case of GO, layers are being spread to $0.8 \mathrm{~nm}\left(11^{\circ}\right)$ due to presence of hydroxyl and epoxy bonds intercalation with carbon layers. Significant decrease in signal intensity of GO is also apparent in comparison to G-band. RGO which was applied into materials as a nanofiller has no visible signals at that $2 \theta$ value probably due to high exfoliation and fragmentation after thermal reduction. However small, broad signal can be observed at $26.4^{\circ}$. That corresponds to $0.34 \mathrm{~nm}$ distance between each layer which means that this material can contain some traces of graphite structures. Characteristic plateau on the diffractogram (Figure 1(a)) shows that graphene oxide lacks significant order in its 


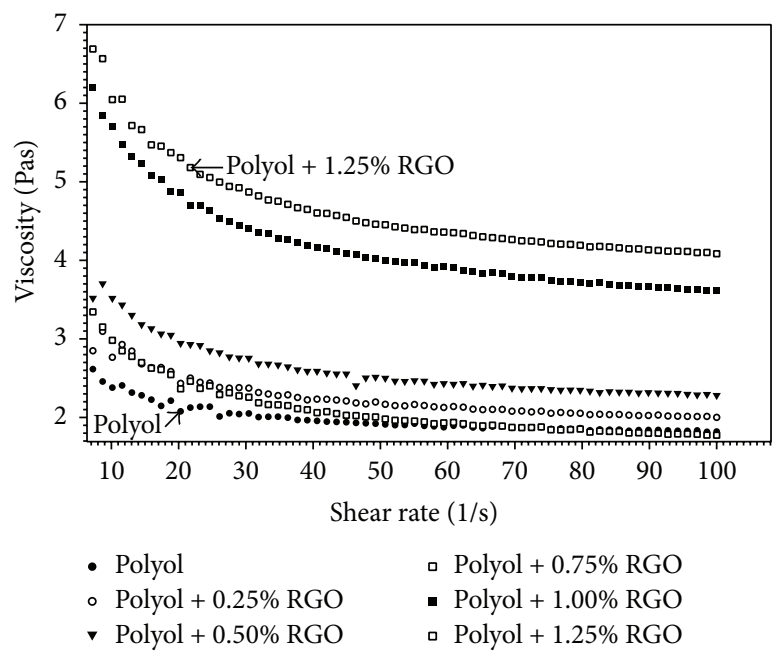

(a)

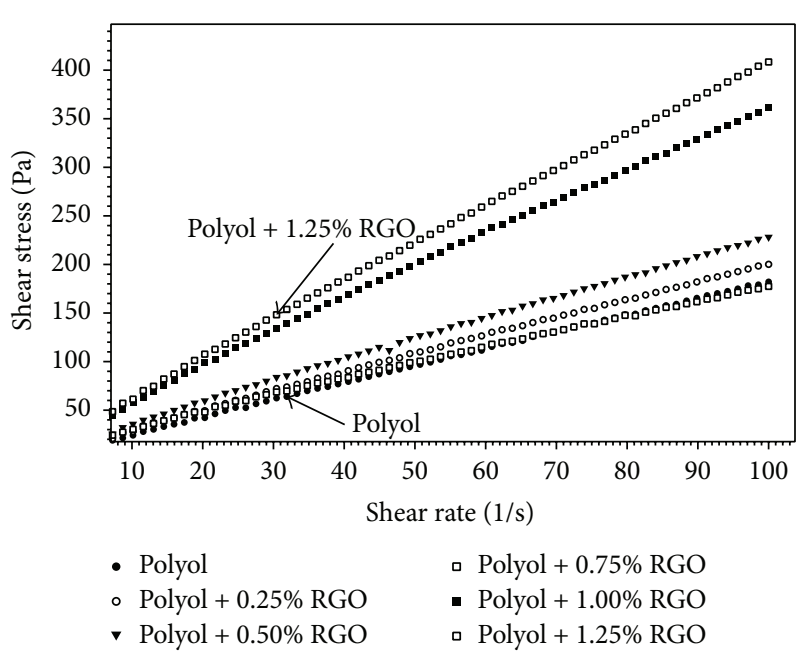

(b)

FIGURE 2: Collective data showing viscosity (a) and sheer stress (b) relations in function of sheer rate. Information was obtained for polyols with nanofiller (RGO) content ranging from 0 to $1,25 \%$ in microporous materials.

internal structure. Obtained results are in good relation with data presented by Cao and Zhang [42].

Figure 1(b) illustrates most prominent results obtained for RGO nanofiller. Raman spectra for GO show D- and G-bands visible at wavenumbers 1350 and $1550 \mathrm{~cm}^{-1}$. Intensity of band $\mathrm{D}$ is related to defects and oxygen bonding present on the surface of GO. G-band is related to the number of conjugated double carbon bonds responsible for conductivity of the material. Reduction of GO to RGO decreases the number of hydroxyl and carboxylic groups apparent at the surface which decreases D-band intensity. However, during thermal reduction, the number of conjugated carbon bands and layers decreases due to exfoliation and desorption (based on XPS analysis the authors calculated oxygen and carbon content, for $\mathrm{GO}, 34.5 \% \mathrm{O}$ and $65.5 \% \mathrm{C}$, and for thermally reduced form RGO, $16.5 \% \mathrm{O}$ and $83.5 \% \mathrm{C}$ ). This in consequence leads to loss in G-band intensity. Investigated ratio $\left(I_{\mathrm{D}} / I_{\mathrm{G}}\right)$ illustrated in Figure 1(b) contributes to scale of disorder present in RGO structure and is inversely proportional to average size of $\mathrm{sp}^{2}$ clusters. The better the RGO ratio in comparison to GO, the more efficient the reduction to $\mathrm{sp}^{2}$ structure. More information about spectroscopy characteristic of RGO nanofiller and polyurethane nanocomposites, especially Raman and FTIR analyses, was presented in our previous publication [44].

2.3. Microporous Synthesis. Microporous polyurethane foams (MPU) were obtained during a laboratory-scale procedure from a three-component $(\mathrm{A}, \mathrm{B}$, and $\mathrm{C})$ system $(\mathrm{MB}$ Market Ltd., Poland). Component A consists of GF422 POL A polyol and RGO (nanofiller). It was prepared by vigorous mechanical stirring for $60 \mathrm{~min}$ at $6000 \mathrm{rpm}$. Subsequent sonication with an ultrasonic homogenizer was performed for another $60 \mathrm{~min}$. In the first step, component $\mathrm{A}$ was mixed with component $\mathrm{B}$, namely, CROSS.MB/40/4 (crosslinking agent). Next, nanoparticulated polyol matrix containing the chain extender and component C, that is, GT 991 ISO (isocyanate), were heated to $60^{\circ} \mathrm{C}$. Then both of these components were mixed at the predetermined mass ratio for $10 \mathrm{~s}$ at $3000 \mathrm{rpm}$ using a dispersing turbine type impeller of $2.5 \mathrm{~cm}$ diameter at $60^{\circ} \mathrm{C}$ and $70 \%$ relative humidity. The resulting reaction mixture was poured into a metal mould of approximate dimensions of $20 \times 100 \times 140 \mathrm{~mm}$, which was closed and heated to $60^{\circ} \mathrm{C}$. All MPU samples were stored at room temperature for $48 \mathrm{~h}$ after demoulding.

Rheological parameters of substrates, used for obtaining polyurethane materials with reduced graphene oxide (GO), were measured by Brookfield R/S Portable rotational steady state controlled shear stress rheometer. Coaxial cylinder measuring system CC-14 (DIN 53019/ISO 3219 norm) was used to register flow and viscosity curves. Measurements were carried out at $50^{\circ} \mathrm{C}$ with shear rate ranging from 0,9 to $100 \mathrm{~s}^{-1}$ within 300 -second timeframe. Analysis of shear stresses and viscosity parameters in function of shear rate provides information about the flow behavior of nanofilled polyols (Figures 2(a) and 2(b)). Rheograms were fitted to Ostwald-de Waele mathematical power law model: $\tau=k$. $\gamma^{n}$, where $\tau$ is the shear stress, $\gamma$ is the shear rate, $k$ is the consistency index, and $n$ is the flow exponent. Viscosity of polyol mixture significantly increases with reduced graphite oxide (RGO) content. This effect is most prominent in mixtures with 1,00 and 1,25\% RGO. Undoubtedly higher nanofiller content is associated with increasing viscosity; this may cause mixing problems during substrate preparation. On the other hand, we can be certain that we have good dispersion in prepared material. Calculated flow exponent is smaller than unity for all measured samples. It means that polyols belong to shear thinning, pseudoplastic liquids. Presence of RGO nanofillers increases consistency and viscosity of polyol mixtures (Figure 2(a)). Decrease of $n$ value as a function of nanofiller concentration means that the substance leans toward more pseudoplastic behavior as a result of specific nanofiller orientation in the investigated material. 
TABLE 1: Temperatures corresponding to 2,5 , and $10 \%$ weight loss and maximum degradation rate $\left(T_{\max }\right)\left( \pm 1^{\circ} \mathrm{C}\right)$ obtained from the first derivative of TGA signal.

\begin{tabular}{lcccc}
\hline Samples $/ \% \mathrm{wt}$ & $T_{2 \%} /{ }^{\circ} \mathrm{C}$ & $T_{5 \%} /{ }^{\circ} \mathrm{C}$ & $T_{10 \%} /{ }^{\circ} \mathrm{C}$ & $T_{\max } /{ }^{\circ} \mathrm{C}$ \\
\hline MPU & 273 & 294 & 319 & 373 \\
MPU $_{0.25 \%}$ & 278 & 296 & 320 & 398 \\
MPU $_{0.50 \%}$ & 284 & 299 & 320 & 399 \\
MPU $_{0.75 \%}$ & 287 & 301 & 320 & 419 \\
$\operatorname{MPU}_{1.0 \%}$ & 284 & 302 & 323 & 424 \\
MPU $_{1.25 \%}$ & 290 & 304 & 326 & 424 \\
\hline
\end{tabular}

2.4. Characterization. The microporous structure of MPU samples was characterized by using a FEI Quanta 250 FEG scanning electron microscope (20 kV, LFD Detector). Samples were cut according to the required dimensions at ambient temperature. Thermogravimetric analysis (TGA) was performed under nitrogen atmosphere on a NETZSCH TG 209 apparatus using $10 \mathrm{mg}$ samples at a temperature range from 40 to $700^{\circ} \mathrm{C}$ and heating rate of $20^{\circ} \mathrm{C} / \mathrm{min}$. The differential scanning calorimetry (DSC) was performed on a DSC 204 F1 Phoenix apparatus under nitrogen atmosphere at a temperature range from -85 to $200^{\circ} \mathrm{C}$. Tensile strength tests were carried out using Zwick/Roell Z020 universal mechanical testing (ISO 527-1). The heating rate was approximately $10^{\circ} \mathrm{C} / \mathrm{min}$. Mechanical properties were measured in a dynamic mode (single cantilever) using a TA DMA Q800 apparatus at a temperature range from -85 to $150^{\circ} \mathrm{C}$, at a heating rate of $4^{\circ} \mathrm{C} / \mathrm{min}$, and at frequency of $10 \mathrm{~Hz}$. Shore hardness type D was estimated by using a Zwick 3131 durometer in accordance with PN-ISO 868. The densities of PU nanocomposite foams were calculated according to ISO 845:2006 (E) based on the measurements of the dimensions and weight of the cubic samples. Water absorption was characterized in accordance with PN-EN ISO $62: 2008$. Dried disks $(20 \mathrm{~mm}$ in diameter and $10 \mathrm{~mm}$ thick) were immersed in distilled water at room temperature for $24 \mathrm{~h}$.

\section{Results and Discussion}

3.1. Thermal Properties. The thermal stability of studied materials was evaluated by thermogravimetric analysis (TGA) and illustrated in Figure 3. Table 1 shows the results obtained from the analysis of TGA curves. It is apparent that the incorporation of reduced graphene oxide into microporous polyurethane matrix caused an increase in thermal stability in comparison to the neat MPU system. Thermogravimetric curves are characteristic for polyurethane systems (Figure 3), where degradation process is connected with urethane bond destruction. Polyurethanes showed an initial weight loss in the range of $210-250^{\circ} \mathrm{C}$. The value of degradation temperature $\mathrm{T}_{2}$ increased by about $17^{\circ} \mathrm{C}$ at $1.25 \mathrm{wt} \%$ of RGO content, compared to the MPU nonmodified systems. Additionally, the maximum of the 1st derivative of TGA curve (DTG) shifted towards higher temperatures with increasing RGO content (Table 1). For the MPU samples containing 1 and $1.25 \%$ of nanofiller, the temperature corresponding to the maximum (DTG) was higher $\left(51^{\circ} \mathrm{C}\right)$ in comparison to the

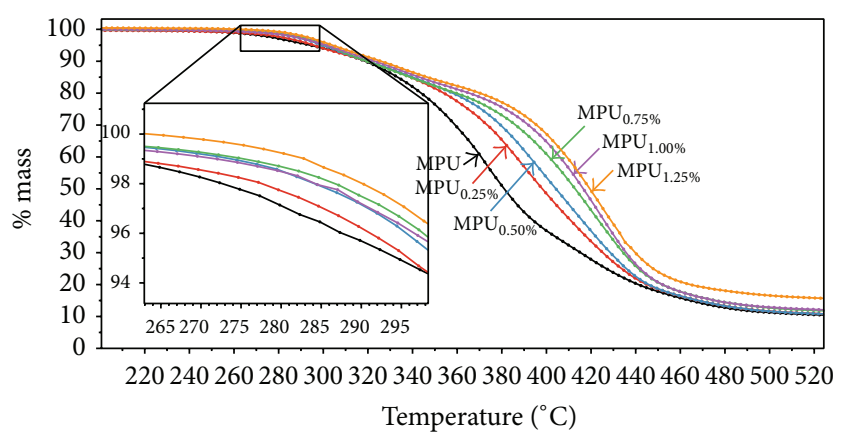

Figure 3: TGA thermograms and \% mass versus temperature.

neat MPU system. Graphene and the reduced form of graphene are both very stable materials that are stiffer than polyurethane matrix. When applying these nanofillers, we can achieve limited chain mobility and can influence thermal stability of nanocomposite systems [43]. Good dispersion and adequate concentration of the nanofiller in polymeric matrix are crucial in order to obtain materials with improved thermal properties.

Thermal analysis was also performed by using DSC technique. It was carried out to characterize changes in the glass transition temperature $\left(T_{q}\right)$ caused by the effect of RGO addition in PU soft segments (Table 2). The addition of RGO had a small influence on $T_{g}$, which increased with increasing RGO content (up to $-19^{\circ} \mathrm{C}$ for $\mathrm{MPU}_{1.25}$ ). The interaction between RGO and the soft segments was weak. Generally, the $T_{g}$ value of the soft segment changes significantly when the functionalized nanofillers react with polymeric matrix. Also, the glass transition temperature, calculated as the maximum of tangent delta, showed a decrease in value with increasing RGO content $\left(1-3^{\circ} \mathrm{C}\right)$.

3.2. Morphological Properties. A microscopic investigation of the studied materials was preformed using TEM and SEM techniques. The obtained RGO displayed a delaminated structure (Figure 5(a)). The microporous nanocomposites containing reduced graphene oxide had good round shape, $100-400 \mu \mathrm{m}$ size, and microporous structure (Figures 5(b)5(d)). Our studies confirmed that larger pore sizes form in microporous materials with increasing content of nanofiller. The addition of RGO nanofiller resulted in a higher presence of pores with more irregular shapes and more defected structure. Increasing the pore size significantly affects the mechanical properties of systems. Introduction to up to $1 \mathrm{wt} \%$ RGO gives a positive effect and improves the mechanical parameters. The water absorption of the system RGO modified samples is presented in Table 2. Higher cell size for modified systems possesses more water absorption, from $14 \%$ for unmodified system (MPU) to $32 \%$ for material with highest RGO content $\left(\mathrm{MPU}_{1.25 \%}\right)$.

3.3. Mechanical Properties. Mechanical behaviors of RGOcontaining nanocomposites were analyzed in dynamic (DMA) and static modes (Zwick/Roell). The dynamic behavior of the nanocomposites shows that, at low RGO 


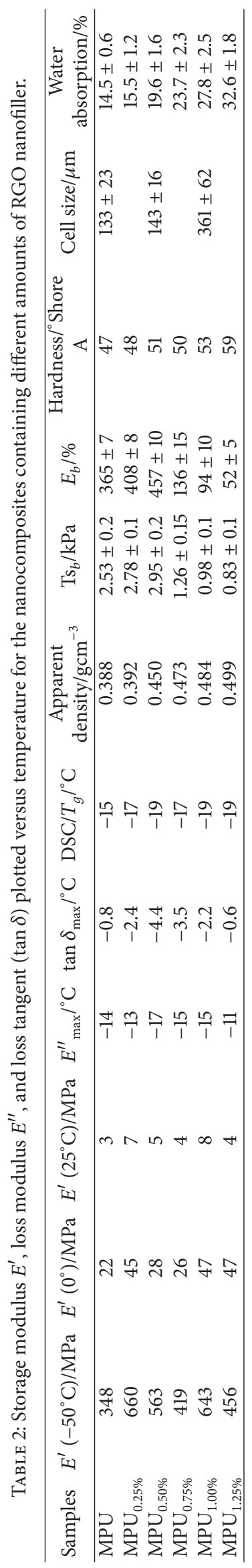




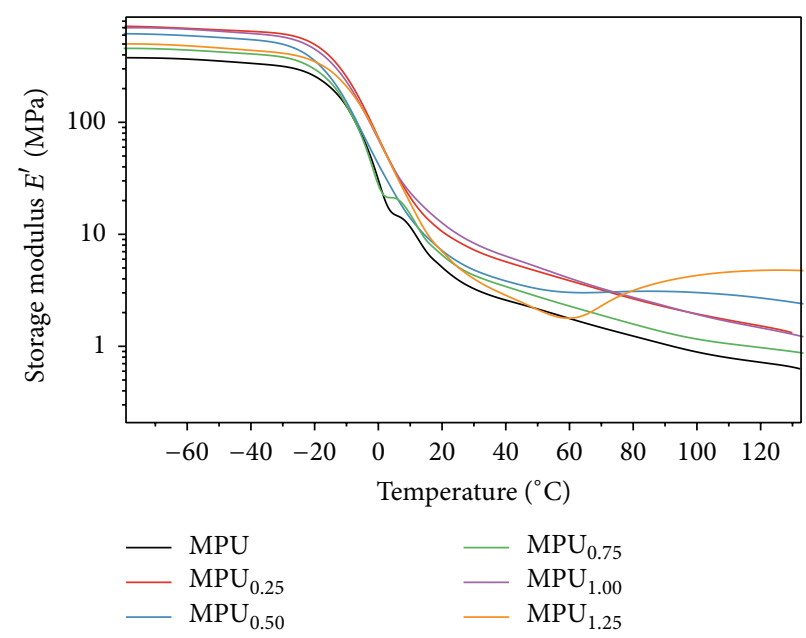

FIgURE 4: Storage modulus $E^{\prime}$, loss modulus $E^{\prime \prime}$, and loss tangent $(\tan \delta)$ plotted as a function of temperature for the nanocomposites containing different amounts of TRG nanofiller.

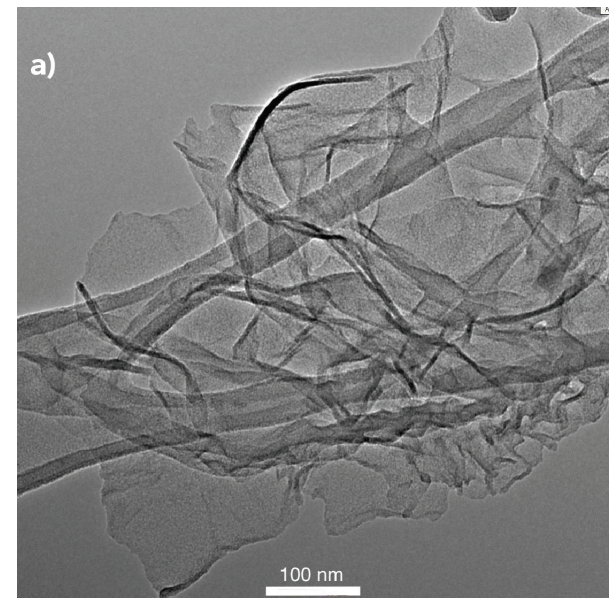

(a)

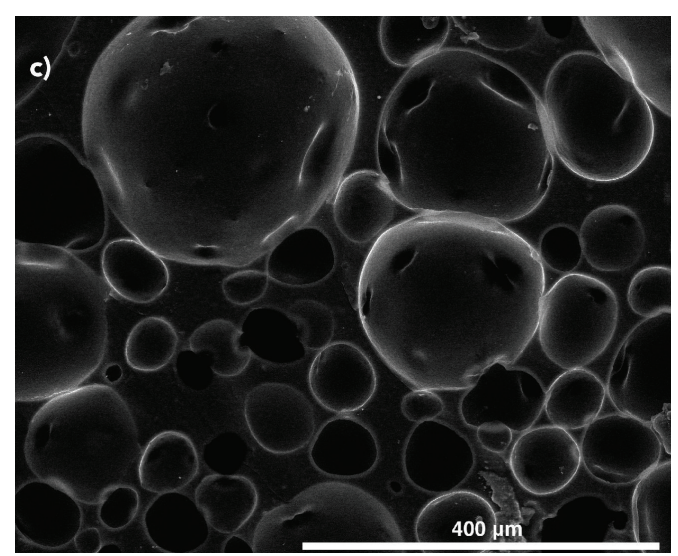

(c)

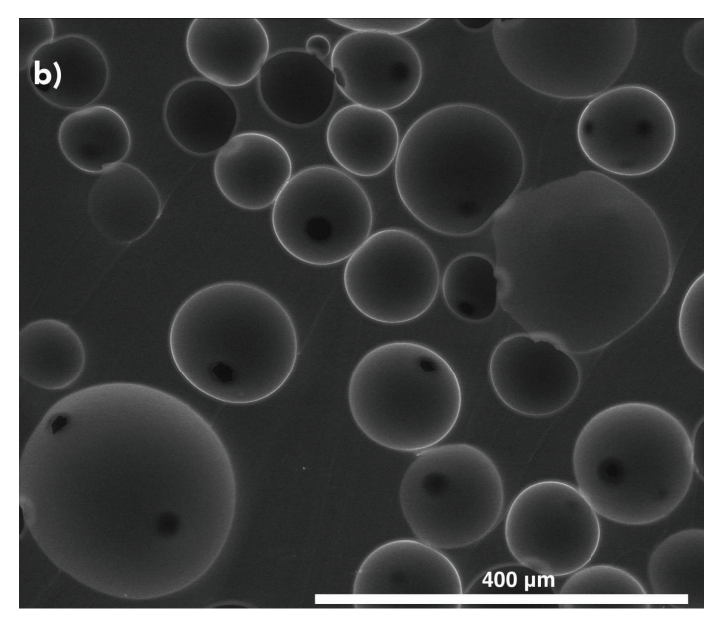

(b)

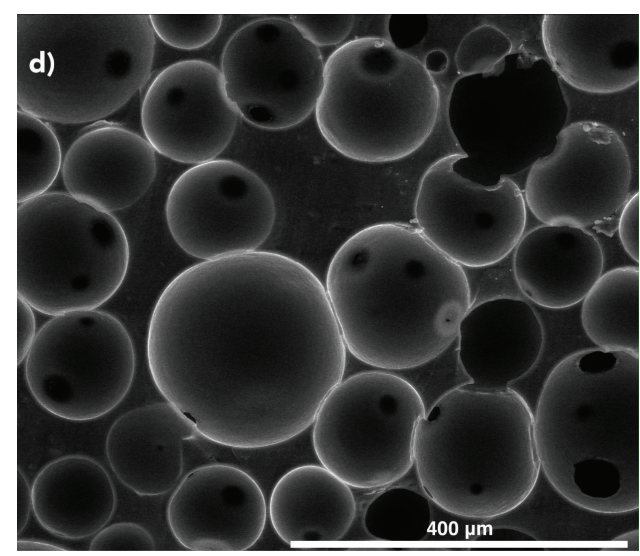

(d)

FIGURE 5: Microimages of (a) reduced graphene oxide (TEM), (b) pure microporous polyurethane (MPU), (c) microporous polyurethane + $0.5 \% \mathrm{RGO}$, and (d) microporous polyurethane $+1 \%$ RGO. 
content, storage modulus is higher than for unmodified system (Figure 4). Probably at low RGO content good percolation can be obtained to cause increase in storage modulus (Table 2). What is very important is the fact that the higher level of $E^{\prime}$ is observed in whole range of measured temperatures, below and above glass transition temperature (Figure 4). Increase in $E^{\prime}$ for samples containing 0.50 and $1.25 \mathrm{wt} \%$ of RGO can be connected with higher mobility chains above glass transition temperature and presence of nanofiller, which promote cold crystallization process with increase of hardness and $E^{\prime}$ at higher temperatures. Also some moisture evaporation above glass transition temperature causes increase in these parameters.

The highest tensile strength was obtained for the materials containing $0.5 \mathrm{wt} \%$ of RGO (Table 2). Higher RGO content of up to $1.25 \mathrm{wt} \%$ affected the mechanical properties of the system that exhibit (30\%) lower values. Elongation at break increased in the samples containing up to $0.5 \mathrm{wt} \%$ of nanofiller, while, for the higher nanofiller content, it significantly decreased. Higher addition (above $1.0 \mathrm{wt} \%$ ) of nanofiller causes a marked reduction in mechanical performance in both static and dynamic modes (Table 2).

The addition of small amounts of modifier (up to $1.25 \mathrm{wt} \%$ of RGO) increased the apparent density and hardness of polyurethane nanocomposites (Table 2). The hardness increased from $47^{\circ}$ Shore A for the unmodified systems to $59{ }^{\circ}$ Shore A for the microporous polyurethane matrix containing $1.25 \mathrm{wt} \%$ of RGO.

\section{Conclusions}

Reduced graphene oxide/polyurethane nanocomposites were successfully prepared without the use of solvent. DSC and TGA experiments were performed in order to characterize the thermal properties of studied materials. The obtained systems displayed enhanced thermal stability. In conclusion, the presented results demonstrate that the incorporation of thermally reduced graphene oxide (RGO) into microporous polyurethane matrix (MPU) can improve the mechanical properties about $17 \%$ for $\mathrm{MPU}_{0.50 \%}$ and thermal stability up to $51^{\circ} \mathrm{C}\left(T_{\max }\right)$ for $\mathrm{MPU}_{1.0 \%}$ and $\mathrm{MPU}_{1.25 \%}$ materials compared to pure polymeric systems. The best results were achieved for the microporous polyurethanes containing $0.5 \mathrm{wt} \%$ of RGO.

\section{Competing Interests}

The authors declare that they have no competing interests.

\section{Acknowledgments}

This research was supported by the GRAF-TECH Program (GRAF-TECH/NCBR/11/08/2013) through the National Centre for Research and Development of Poland.

\section{References}

[1] C. Lee, X. Wei, J. W. Kysar, and J. Hone, "Measurement of the elastic properties and intrinsic strength of monolayer graphene," Science, vol. 321, no. 5887, pp. 385-388, 2008.
[2] A. Balandin, S. Ghosh, W. Bao et al., "Superior thermal conductivity of single-layer graphene," Nano Letters, vol. 8, no. 3, pp. 902-907, 2008.

[3] T. Kuilla, S. Bhadra, D. Yao, N. H. Kim, S. Bose, and J. H. Lee, "Recent advances in graphene based polymer composites," Progress in Polymer Science, vol. 35, no. 11, pp. 1350-1375, 2010.

[4] B. Marinho, M. Ghislandi, E. Tkalya, C. E. Koning, and G. de With, "Electrical conductivity of compacts of graphene, multiwall carbon nanotubes, carbon black, and graphite powder," Powder Technology, vol. 221, pp. 351-358, 2012.

[5] C. Berger, Z. Song, X. Li et al., "Electronic confinement and coherence in patterned epitaxial graphene," Science, vol. 312, no. 5777, pp. 1191-1196, 2006.

[6] M. Y. Han, B. Özyilmaz, Y. Zhang, and P. Kim, "Energy bandgap engineering of graphene nanoribbons," Physical Review Letters, vol. 98, no. 20, Article ID 206805, 2007.

[7] X. Wang, Y. Ouyang, X. Li, H. Wang, J. Guo, and H. Dai, "Room-temperature all-semiconducting sub-10-nm graphene nanoribbon field-effect transistors," Physical Review Letters, vol. 100, no. 20, Article ID 206803, 2008.

[8] Q. Shao, G. Liu, D. Teweldebrhan, and A. A. Balandin, "Higherature quenching of electrical resistance in graphene interconnects," Applied Physics Letters, vol. 92, no. 19, Article ID 192117, 2008.

[9] S. Ghosh, I. Calizo, D. Teweldebrhan et al., "Extremely high thermal conductivity of graphene: prospects for thermal management applications in nanoelectronic circuits," Applied Physics Letters, vol. 92, no. 15, Article ID 151911, 2008.

[10] J. H. Seol, I. Jo, A. L. Moore et al., "Two-dimensional phonon transport in supported graphene," Science, vol. 328, no. 5975, pp. 213-216, 2010.

[11] A. A. Balandin, "Thermal properties of graphene and nanostructured carbon materials," Nature Materials, vol. 10, no. 8, pp. 569-581, 2011.

[12] E. Yoo and H. Zhou, "Li-air rechargeable battery based on metal-free graphene nanosheet catalysts," ACS Nano, vol. 5, no. 4, pp. 3020-3026, 2011.

[13] S. M. Oh, K. M. Oh, T. D. Dao, H.-I. Lee, H. M. Jeong, and B. K. Kim, "The modification of graphene with alcohols and its use in shape memory polyurethane composites," Polymer International, vol. 62, no. 1, pp. 54-63, 2013.

[14] M. J. Allen, V. C. Tung, and R. B. Kaner, "Honeycomb carbon: a review of graphene," Chemical Reviews, vol. 110, no. 1, pp. 132$145,2010$.

[15] C. N. R. Rao, A. K. Sood, K. S. Subrahmanyam, and A. Govindaraj, "Graphene: the new two-dimensional nanomaterial," Angewandte Chemie - International Edition, vol. 48, no. 42, pp. 7752-7777, 2009.

[16] A. H. Castro Neto, F. Guinea, N. M. R. Peres, K. S. Novoselov, and A. K. Geim, "The electronic properties of graphene," Reviews of Modern Physics, vol. 81, no. 1, pp. 109-162, 2009.

[17] D. R. Dreyer, R. S. Ruoff, and C. W. Bielawski, "From conception to realization: an historial account of graphene and some perspectives for its future," Angewandte Chemie-International Edition, vol. 49, no. 49, pp. 9336-9344, 2010.

[18] B. Ramezanzadeh, E. Ghasemi, M. Mahdavian, E. Changizi, and M. H. Mohamadzadeh Moghadam, "Characterization of covalently-grafted polyisocyanate chains onto graphene oxide for polyurethane composites with improved mechanical properties," Chemical Engineering Journal, vol. 281, pp. 869-883, 2015. 
[19] B. Tan and N. Thomas, "A review of the water barrier properties of polymer/clay and polymer/graphene nanocomposites," Journal of Membrane Science, vol. 514, pp. 595-612, 2016.

[20] H. Liu, P. Bandyopadhyay, N. H. Kim, B. Moon, and J. H. Lee, "Surface modified graphene oxide/poly(vinyl alcohol) composite for enhanced hydrogen gas barrier film," Polymer Testing, vol. 50, pp. 49-56, 2016.

[21] K. K. Sadasivuni, D. Ponnamma, B. Kumar et al., "Dielectric properties of modified graphene oxide filled polyurethane nanocomposites and its correlation with rheology," Composites Science and Technology, vol. 104, pp. 18-25, 2014.

[22] K. K. Sadasivuni, D. Ponnamma, S. Thomas, and Y. Grohens, "Evolution from graphite to graphene elastomer composites," Progress in Polymer Science, vol. 39, no. 4, pp. 749-780, 2014.

[23] Q. Jing, W. Liu, Y. Pan, V. V. Silberschmidt, L. Li, and Z. Dong, "Chemical functionalization of graphene oxide for improving mechanical and thermal properties of polyurethane composites," Materials \& Design, vol. 85, pp. 808-814, 2015.

[24] A. K. Geim, "Graphene: status and prospects," Science, vol. 324, no. 5934, pp. 1530-1534, 2009.

[25] D. Cai, K. Yusoh, and M. Song, "The mechanical properties and morphology of a graphite oxide nanoplatelet/polyurethane composite," Nanotechnology, vol. 20, no. 8, Article ID 085712, 2009.

[26] S. Park and R. S. Ruoff, "Chemical methods for the production of graphenes," Nature Nanotechnology, vol. 4, no. 4, pp. 217-224, 2009.

[27] D. C. Marcano, D. V. Kosynkin, J. M. Berlin et al., "Improved synthesis of graphene oxide," ACS Nano, vol. 4, no. 8, pp. 48064814, 2010.

[28] J. Xiong, Y. Liu, X. Yang, and X. Wang, "Thermal and mechanical properties of polyurethane/montmorillonite nanocomposites based on a novel reactive modifier," Polymer Degradation and Stability, vol. 86, no. 3, pp. 549-555, 2004.

[29] X. Gao, H. Yue, E. Guo et al., "Mechanical properties and thermal conductivity of graphene reinforced copper matrix composites," Powder Technology, vol. 301, pp. 601-607, 2016.

[30] H. J. Yoo, S. S. Mahapatra, and J. W. Cho, "High-speed actuation and mechanical properties of graphene-incorporated shape memory polyurethane nanofibers," Journal of Physical Chemistry C, vol. 118, no. 19, pp. 10408-10415, 2014.

[31] P. Pokharel and D. S. Lee, "High performance polyurethane nanocomposite films prepared from a masterbatch of graphene oxide in polyether polyol," Chemical Engineering Journal, vol. 253, pp. 356-365, 2014.

[32] B. Yu, X. Wang, W. Xing et al., "Enhanced thermal and mechanical properties of functionalized graphene/thiol-ene systems by photopolymerization technology," Chemical Engineering Journal, vol. 228, pp. 318-326, 2013.

[33] H. Kim, A. A. Abdala, and C. W. MacOsko, "Graphene/polymer nanocomposites," Macromolecules, vol. 43, no. 16, pp. 65156530, 2010.

[34] G. Carotenuto, V. Romeo, I. Cannavaro, D. Roncato, B. Martorana, and M. Gosso, "Graphene-polymer composites," Materials Science and Engineering, vol. 40, pp. 12-18, 2012.

[35] A. S. Patole, S. P. Patole, S.-Y. Jung, J.-B. Yoo, J.-H. An, and T.-H. Kim, "Self assembled graphene/carbon nanotube/polystyrene hybrid nanocomposite by in situ microemulsion polymerization," European Polymer Journal, vol. 48, no. 2, pp. 252-259, 2012.
[36] A.-K. Appel, R. Thomann, and R. Mülhaupt, "Polyurethane nanocomposites prepared from solvent-free stable dispersions of functionalized graphene nanosheets in polyols," Polymer, vol. 53, no. 22, pp. 4931-4939, 2012.

[37] D. Cai, J. Jin, K. Yusoh, R. Rafiq, and M. Song, "High performance polyurethane/functionalized graphene nanocomposites with improved mechanical and thermal properties," Composites Science and Technology, vol. 72, no. 6, pp. 702-707, 2012.

[38] D. A. Nguyen, Y. R. Lee, A. V. Raghu, H. M. Jeong, C. M. Shin, and B. K. Kim, "Morphological and physical properties of a thermoplastic polyurethane reinforced with functionalized graphene sheet," Polymer International, vol. 58, no. 4, pp. 412417, 2009.

[39] U. Khan, P. May, A. O’Neill, and J. N. Coleman, "Development of stiff, strong, yet tough composites by the addition of solvent exfoliated graphene to polyurethane," Carbon, vol. 48, no. 14, pp. 4035-4041, 2010.

[40] I. S. Fahim, W. Mamdouh, T. M. Madkour, and H. A. G. Salem, "A nanoscale investigation of mechanical, thermal stability and electrical conductivity properties of reinforced thermoplastic polyurethane/graphene nanocomposite," American Journal of Nanoscience and Nanotechnology, vol. 1, no. 1, pp. 31-40, 2013.

[41] M. Kumar, J. S. Chung, B.-S. Kong, E. J. Kim, and S. H. Hur, "Synthesis of graphene-polyurethane nanocomposite using highly functionalized graphene oxide as pseudo-crosslinker," Materials Letters, vol. 106, pp. 319-321, 2013.

[42] N. Cao and Y. Zhang, "Study of reduced graphene oxide preparation by Hummers' method and related characterization," Journal of Nanomaterials, vol. 2015, Article ID 168125, 5 pages, 2015.

[43] F. C. De Fim, N. R. S. Basso, A. P. Graebin, D. S. Azambuja, and G. B. Galland, "Thermal, electrical, and mechanical properties of polyethylene-graphene nanocomposites obtained by in situ polymerization," Journal of Applied Polymer Science, vol. 128, no. 5, pp. 2630-2637, 2013.

[44] M. Strankowski, D. Włodarczyk, Ł. Piszczyk, and J. Strankowska, "Polyurethane nanocomposites containing reduced graphene oxide, FTIR, raman, and XRD studies," Journal of Spectroscopy, vol. 2016, Article ID 7520741, 6 pages, 2016. 

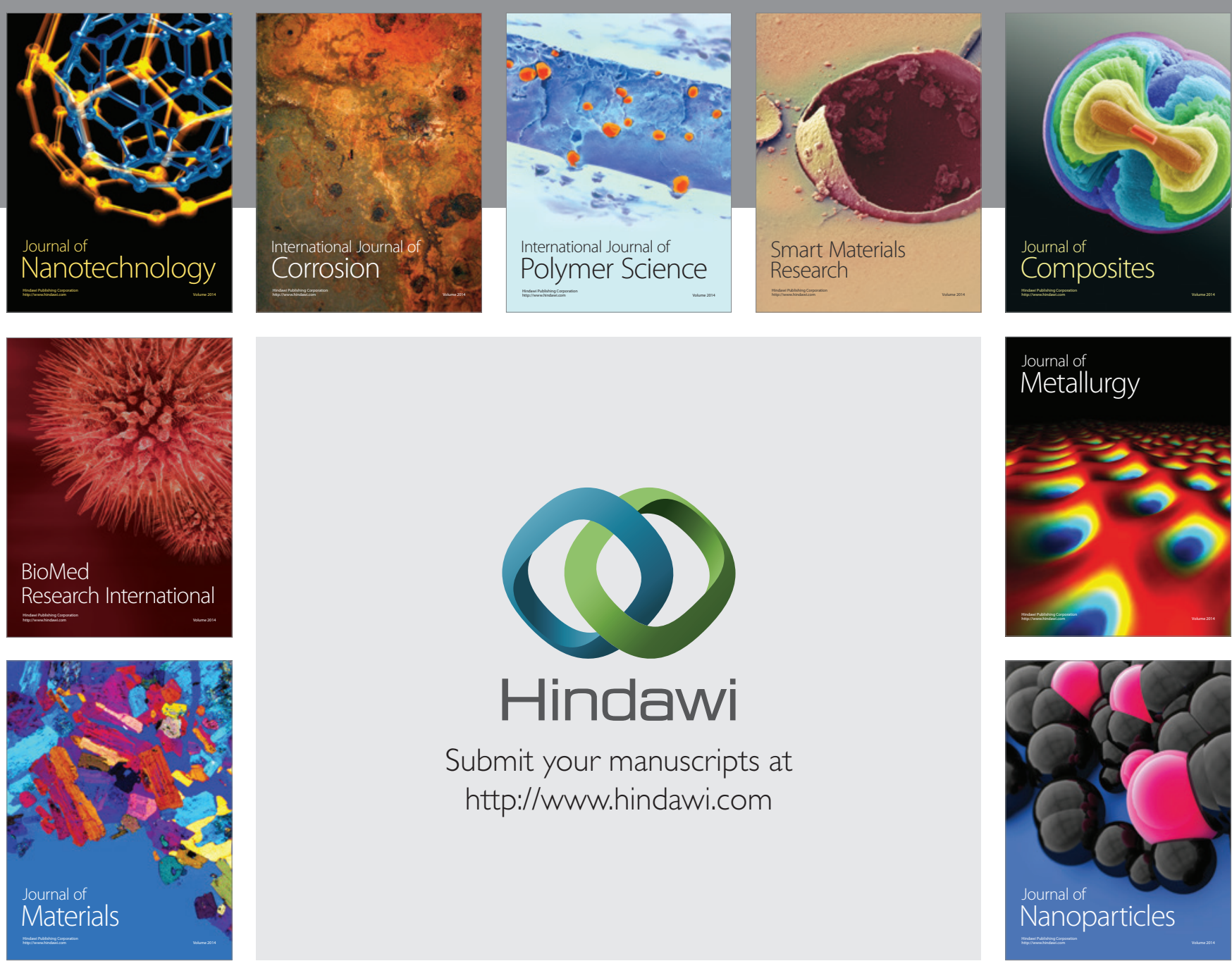

\section{Hindawi}

Submit your manuscripts at

http://www.hindawi.com

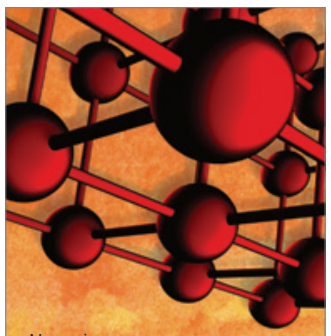

Materials Science and Engineering
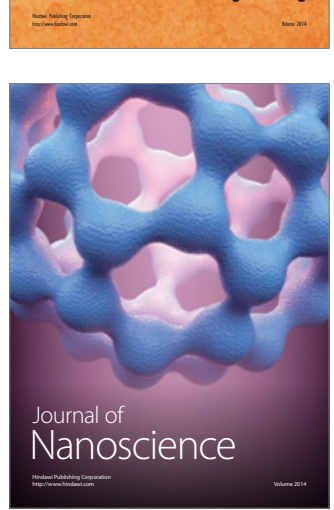
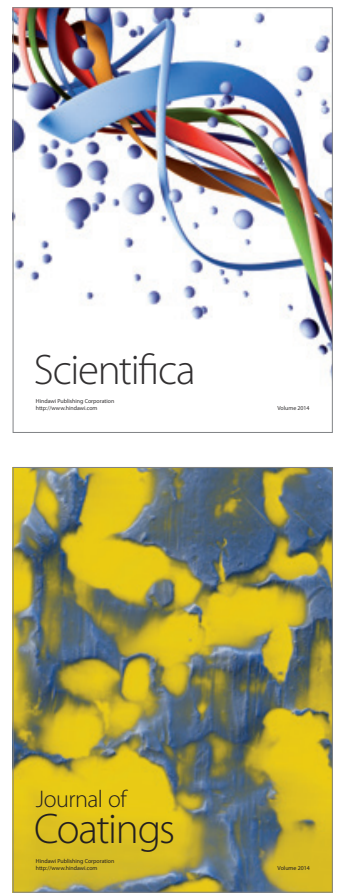
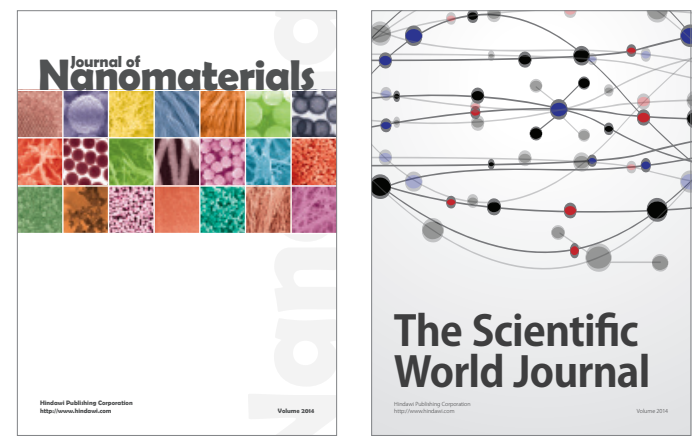

The Scientific World Journal
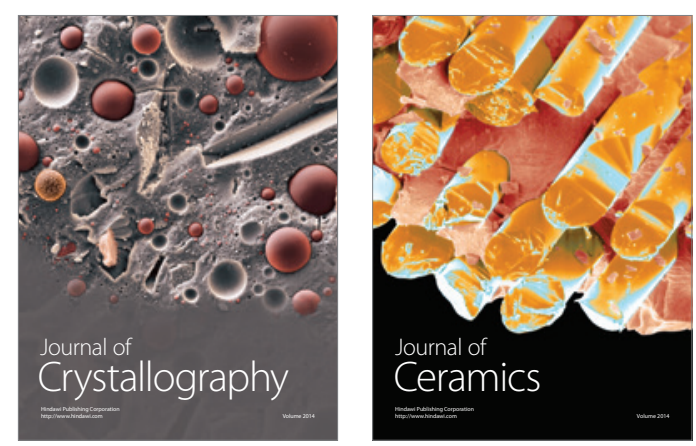
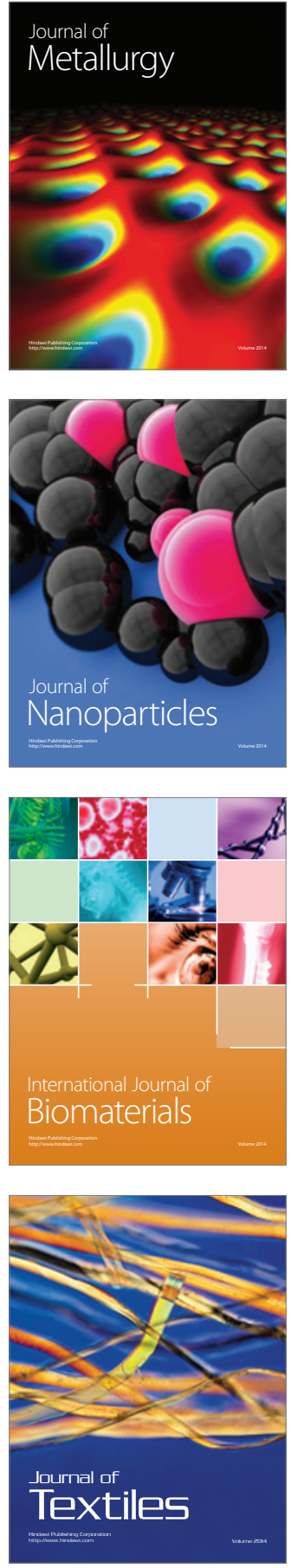